to appear in Combustion and Flame (2006)

\title{
Application of Genetic Algorithms and Thermogravimetry to Determine the Kinetics of Polyurethane Foam in Smoldering Combustion
}

\author{
Guillermo Rein*, Chris Lautenberger, A. Carlos Fernandez-Pello** \\ Department of Mechanical Engineering, University of California at Berkeley, CA 94720, \\ USA \\ Jose L. Torero \\ University of Edinburgh, UK \\ David L. Urban \\ NASA Glenn Research Center, USA
}

\begin{abstract}
In this work, the kinetic parameters governing the thermal and oxidative degradation of flexible polyurethane foam are determined using thermogravimetric data and a genetic algorithm. These kinetic parameters are needed in the theoretical modeling of the foam's smoldering behavior. Experimental thermogravimetric mass-loss data are used to explore the kinetics of polyurethane foam and to propose a mechanism consisting of five reactions. A lumped model of solid mass-loss based on Arrhenius-type reaction rates and the five-step mechanism is developed to predict the polyurethane thermal degradation. The predictions are compared to the thermogravimetric measurements, and using a genetic algorithm, the method finds the kinetic and stoichiometric parameters that provide the best agreement between the lumped model and the experiments. To date, no study has attempted to describe both forward and opposed smolder-propagation with the same kinetic mechanism. Thus, in order to verify that the polyurethane kinetics determined from thermogravimetric experiments can be used to describe the reactions involved in polyurethane smoldering combustion, the five-step mechanism and its kinetic parameters are incorporated into a simple species model of smoldering combustion. It is shown that the species model agrees with experimental observations and that it captures phenomenologically the spatial distribution of the different species and the reactions in the vicinity of the front, for both forward and opposed propagation. The results indicate that the kinetic scheme proposed here is the first one to describe smoldering combustion of polyurethane in both propagation modes.
\end{abstract}

Keywords: Genetic algorithms; Polyurethane foam; Smoldering combustion; Kinetics;

Thermogravimetry.

* Current affiliation: School of Engineering and Electronics, University of Edinburgh, EH9 3JL, UK.

** Corresponding author; e-mail: ferpello@me.berkeley.edu; fax: +01 5106421850 


\title{
.Nomenclature
}

\author{
$\mathrm{A}_{\mathrm{i}} \quad$ Pre-exponential factor of reaction $\mathrm{i}$ \\ Da Damkohler number \\ $\mathrm{E}_{\mathrm{i}} \quad$ Activation energy of reaction $\mathrm{i}$ \\ hr Heating rate \\ L Characteristic thickness of the smolder front \\ $\mathrm{L}_{\mathrm{t}} \quad$ Characteristic thermal-thickness of the smolder front \\ $\mathrm{M}_{0} \quad$ Initial total mass of solid \\ $\mathrm{M}_{\mathrm{j}} \quad$ Mass of solid species $\mathrm{j}$ \\ $\mathrm{m} \quad$ Fraction of total solid mass respect to initial total mass \\ $\mathrm{m}_{\mathrm{j}} \quad$ Fraction of mass of solid species $\mathrm{j}$ respect to initial total mass \\ $n_{i} \quad$ Power-law parameter for of reaction $i$ \\ $\mathrm{R} \quad$ Universal gas constant \\ t Time \\ T Temperature \\ u Velocity \\ $\mathrm{y}_{\mathrm{O}_{2}} \quad$ Oxygen mass fraction in gas
}

\section{Greek symbols}

$\alpha \quad$ Ratio of smolder thickness to thermal thickness

$\gamma \quad$ Constant of relative influence in the fitness

$v_{\mathrm{j}, \mathrm{i}} \quad$ Mass yield/consumption of species $\mathrm{j}$ per mass of reactant in reaction $\mathrm{i}$

$\Phi \quad$ Fitness of individual

$\delta \quad$ Binary exponent for the oxygen fraction dependence

$\rho \quad$ Density

$\xi \quad$ Non-dimensional spatial location

$\dot{\omega}_{\mathrm{j}} \quad$ Reaction rate of reaction $\mathrm{j}$

$\dot{\theta}_{j} \quad$ Non-dimensional reaction rate of reaction $\mathrm{j}$

$\Pi \quad$ Non-dimensional temperature

$\tau \quad$ Characteristic chemical time

$\phi \quad$ Porosity

\section{Subscripts}

$0 \quad$ Initial

$\beta \quad \beta$-foam solid species

c Char solid species / Char oxidation reaction

calc Calculations

cel Cellulose solid species

exp Experimental

f Foam solid species

fwd Forward propagation

g Gas

$\mathrm{O}_{2} \quad$ Oxygen

o Foam oxidation reaction

o $\beta \quad \beta$-foam oxidation reaction 
opp Opposed propagation

$\mathrm{p} \quad$ Foam pyrolysis reaction

$\mathrm{p} \beta \quad \beta$-foam pyrolysis reaction

$r \quad$ Residue solid species

sml Smolder 


\section{Introduction}

Smoldering phenomenon is a flameless form of combustion, deriving its heat from heterogeneous reactions occurring on the surface of a solid fuel when this is heated in the presence of oxygen [1,2]. It is of interest both as a fundamental combustion problem and as a practical fire hazard. Many materials can sustain a smoldering reaction, including coal, cotton, duff, peat, wood and most charring polymers. A smoldering front can propagate inside a porous combustible material if it is sufficiently permeable to flow. Typically, smoldering initiation requires the external supply of heat to the solid fuel. The subsequent temperature increase of the solid triggers its thermal-degradation reactions (endothermic pyrolysis and exothermic oxidations). The reaction starts to propagate when the net heat released rate is high enough to balance the heat transfer rate ahead of the front and to the surroundings [1,2]. A smoldering combustion reaction is generally oxygen deficient and leaves behind a significant amount of combustible char. The characteristic temperature and heat released during smoldering combustion are low in comparison with flaming combustion, and the smoldering front propagates at speeds that are two orders of magnitude lower than flame spread. In spite of its weak-combustion characteristics, smoldering incidents represent an important fire-safety hazard because it can be initiated by relatively weak sources of heat, it yields a high conversion to toxic gases, it is difficult to detect and extinguish within the interior of porous materials, and it can abruptly transition to flaming combustion. Fire statistics draw attention on the magnitude of smoldering fires as the leading cause of fire deaths [3]. More than $25 \%$ of the annual firedeaths in the USA are attributed to smoldering-initiated fires, both due to a sudden transition from smoldering to flaming combustion and a higher conversion to toxic species per mass of fuel (e.g. carbon monoxide). Only during 2001, in the USA there were an estimated 31,200 smoldering fires causing a total of \$386 million in property damage [3]. In spite of this, smoldering combustion receives relatively little attention from the firesafety community. A possible explanation for this fact is that the menace of smoldering fires generally originates from the objects inside a building rather than the building itself, and thus it is perceived as a consumer-product oriented issue and not a building-codes issue.

Smoldering combustion is also of concern in space flight programs. The Space Shuttles have registered an average of one charred-cable incident for every ten missions [4, 5]. A charred cable is symptomatic of smolder-prone conditions and could lead to sustained smoldering combustion or ignition of nearby fuels. Also the MIR orbital station and other 
Soviet/Russian spacecrafts suffered several smolder-related incidents [6]. With the currently orbiting International Space Station and future long-term manned missions (Moon and Mars), it is important to understand the mechanisms of smoldering combustion in a variety of practical materials, both in microgravity and normal gravity, so that the fire hazard posed by smoldering fires can be mitigated.

Modeling of smolder is of particular interest due to its potential use for estimating smolder-ignition resistance, the production rate of toxic species, conditions for transition to flaming, and for forensic fire reconstruction. It also provides a cost-effective alternative to experiments when testing is too costly, such as in reduced gravity environments. In addition to the thermophysical aspects of smoldering combustion, inclusion of the chemical reactions occurring on the solid fuel is important when modeling in detail the smoldering phenomenon. Kinetics governs the chemical structure of the front, dictates the global heat-released rate, and is ultimately responsible for determining under what conditions a material ignites and smolders (and thus poses a hazard). Proper computation of the reaction rates is particularly essential for the kinetically controlled regimes of ignition, extinction, and the transition to flaming. Thus, advanced models of smoldering combustion require quantitative information on the heterogeneous reactions taking place in the solid. However, it is difficult to establish and quantify the kinetic mechanism of solid degradation with certainty, especially for materials with complex kinetics (multi-step decomposition) like most polymers. Well-established and quantified kinetic mechanisms for smoldering combustion are not readily available in the literature for most fuels of interest

The objective of this work is to develop a methodology to obtain a global mechanism of thermo-oxidative decomposition that can be applied to, in special, computer modeling of smoldering combustion. Emphasis is given to the thermal and oxidative degradation of the solid fuel because these are the most important reactions involved in smoldering combustion [1]. The solid fuel of interest in this work is open-cell, flexible, polyurethane foam (PU), which is selected for several reasons: it is of major importance in residential and industrial fire-safety; it is a good representative of smolder-prone porous materials; it has homogeneous properties and is easy to handle in laboratory experiments; and a significant amount of fundamental work has been carried out on it already (including unique microgravity tests), so this work benefits from ample existing knowledge.

PU is a class of versatile polymers produced by the reaction of a polyol with an isocyanate plus catalysts, surfactants and water. In the form of foam, it is used in a wide 
range of industrial applications with worldwide production over a million tons per year. The aeronautics, automobile, construction and furniture industrial sectors use it to manufacture thermal insulation, upholstery, as well as sound and shock dampening materials. PU foam is a major fire-safety concern $[3,7,8]$ due to its relatively low ignition resistance, being a common fire-ignition source through smoldering combustion and a latter transition to flaming combustion.

Most of the studies on PU solid thermal-decomposition do not provide all the information needed to model smoldering combustion. They usually focus on thermaldecomposition by pyrolysis only [9, 10,11] (and thus the kinetic scheme is incomplete for oxidative environments), or provide kinetic parameters that are not appropriate for numerical models $[12,13]$. Some authors modeling smolder of PU used the kinetic parameters of other polymeric fuels $[14,15]$ or/and use calibration procedures to extract some unknown parameters [15, 16]. Furthermore, conventional mechanisms do not describe both smolder-propagation modes (opposed or forward). Consequently, different mechanisms are used for each propagation mode (e.g. [17, 18]). Since there are no fundamental kinetic differences between the two propagation modes, a single comprehensive kinetic scheme should describe both adequately.

In this work, a comprehensive and quantitative mechanism is proposed that is valid for modeling PU smoldering behavior in both opposed and forward propagation. First a global mechanism of PU kinetics with five reactions is proposed based on the results from previous thermogravimetric experiments. Then, a lumped model of solid mass-loss is developed and used with the proposed mechanism to numerically reproduce the thermogravimetric experiments. A robust optimization technique (based on genetic algorithm) is used to find the set of kinetic parameters that provide the best agreement between the predictions and the experiments. Then, the mechanism is evaluated by simulating both forward and opposed smolder propagation with a simple one-dimensional model of the reactions inside a smoldering front and comparing the results with experimental observations.

\section{Thermogravimetry and Kinetics Parameters}

The degradation of polymers in general, and of PU in particular, involves complex pathways to chemical and physical changes. An example of the changes in the microscale morphology of PU as it smolders can be seen Fig. 1, which shows scanning electron 
microscopy (SEM) images. The virgin foam (Fig. 1a) has a well-organized distribution of hollow pores of polygonal faces, which are formed by fibers of near-uniform thickness. When the foam pyrolyzes at temperatures between 250 and $300{ }^{\circ} \mathrm{C}$ (Fig. 1b), the distribution of pores changes and the fibers' edges deform toward membraned shapes. The char remaining after smoldering at temperatures between 400 and $450{ }^{\circ} \mathrm{C}$ (Fig. 1c) is comprised of needle-like fibers and no longer has a uniform structure. The successive loss of mass as the foam smolders is evident.

The study of the chemical reactivity of a solid material as it is heated is best carried out experimentally through thermogravimetry (TG). TG is a testing procedure in which changes in the weight of a small solid specimen are recorded as it is heated inside an oven under controlled temperature and composition atmosphere. It provides qualitative and quantitative information regarding the different reactions taking place in the heated solid and is widely used to study solid thermal-degradation. Typical results from TG analysis are the mass $(\mathrm{m})$ and the mass-loss rate $(\mathrm{dm} / \mathrm{dt})$ of the solid at the corresponding temperature of the oven. Once a kinetic mechanism is proposed, the estimation of the corresponding kinetic parameters from TG experimental data can be done with a variety of techniques available in the literature $(20,21)$. For example, for one-step mechanisms, the simplest analytical method consists on correlating experimental data with a linear expression between the logarithm of the reaction rate and the inverse of the temperature [22].

In spite of PU's complex kinetic-behavior, experimental evidence suggests that a mechanism consisting of only a few global reactions would capture the most important characteristics of the decomposition process. Ohlemiller [1] proposed a three-step mechanism for the smoldering combustion of charring polymers (based on the kinetics of cellulose). This mechanism includes fuel pyrolysis, fuel oxidation and char oxidation, accounting for three solid species; fuel, char and ash. The kinetic parameters of PU foam corresponding to this mechanism were calculated by the present authors and applied to model smoldering combustion in [16] (also [23] used these kinetic parameters) with relatively good results. However, since only a single pyrolysis-step was included, the mechanism resulted in excessive mass-loss while underpredicting the oxidation rates.

The TG experiments of Chao and Wang [13] for PU flexible foam suggest that a five-step mechanism would describe better the PU thermal decomposition. By examining the TG results in nitrogen atmosphere (Fig. 2), it can be seen that (at least) two distinct pyrolysis reactions are taking place instead of one. Other TG analyses also confirm that PU pyrolysis 
occurs in two stages $[9,24,25]$. Thus, the three-step mechanism referred to above could be improved with an additional pyrolysis path and with the inclusion of an additional solid species, referred to here as $\beta$-foam. The inclusion of the $\beta$-foam implies the addition of its subsequent oxidation to char. The TG experiments in air atmosphere (Fig. 3) show three peaks in the solid mass-loss rate between 25 and $400{ }^{\circ} \mathrm{C}$. The mechanism then suggests that each peak is the mass-loss of a corresponding solid species by competing pyrolysis and oxidation pathways. This way, the first peak would be the mass-loss of the virgin foam, the second that of the $\beta$-foam, and the third one that of the char. To account for the small mass left at $450{ }^{\circ} \mathrm{C}$, a fourth solid species has to be included, which it is referred here as residue.

Thus, based on the data of Chao and Wang [13], a five-step mechanism is proposed here that is composed of: two foam pyrolysis (Eqs. 1 and 2); two foam oxidations (Eqs. 3) and 4); and one char oxidation (Eq. 5), accounting for four solid species: foam, $\beta$-foam, char and residue.

$$
\begin{aligned}
& \text { Foam } \rightarrow \mathrm{v}_{\beta, p} \beta \text {-foam }+\mathrm{v}_{g, p} \text { Gas } \\
& \beta-\text { foam } \rightarrow \mathrm{v}_{c, p \beta} \text { Char }+\mathrm{v}_{g, p \beta} \text { Gas } \\
& \text { Foam }+\mathrm{v}_{O_{2}, o} O_{2} \rightarrow \mathrm{v}_{c, o} \text { Char }+\mathrm{v}_{g, o} \text { Gas } \\
& \beta-\text { foam }+\mathrm{v}_{O_{2}, o} O_{2} \rightarrow \mathrm{v}_{c, o} \text { Char }+\mathrm{v}_{g, o} \text { Gas } \\
& \text { Char }+\mathrm{v}_{O_{2}, c} O_{2} \rightarrow \mathrm{v}_{r, c} \text { Residue }+\mathrm{v}_{g, c} \text { Gas }
\end{aligned}
$$

The two main constituents of PU are isocyanate and polyol. The major breakdown mechanism in PU is the scission of the polyol-isocyanate bond. The isocyanate vaporizes and the polyol remains to further decompose [9, 26]. Consequently, in the above globalmechanism, the first pyrolysis reaction (Eq. 1) represents the scission of the polyolisocyanate bond, and the $\beta$-foam corresponds to the less-volatile polyol left behind. The polyol further pyrolyzes by the consecutive reaction in Eq. (2). To keep the mechanism as simple as possible but still comprehensive, the oxidation reactions of virgin PU (Eq. 3) and $\beta$-foam (Eq. 4) are assumed to have the same kinetic parameters. Also for simplicity the produced char in Eq. (3) and (4) is assumed to be the same species as the char produced by foam oxidation in Eq. (2). 


\section{Mass-Loss Model and Inverse Problem}

In order to implement the mechanism proposed above (Eqs. 1-5) into numerical models of smoldering, it is necessary to quantify the stoichiometric and kinetic parameters of each reaction. Traditional methods of parameter estimation from TG data become inefficient or impossible to apply for multiple-step reaction mechanisms, such as the one proposed here for PU. Therefore, a more general method that can be applied to any mass-loss mechanism expressible in mathematical terms is implemented in this section. A lumped model of the mass-loss processes is developed to simulate the transient decomposition during TG experiments according to the above mechanism. Then, the results are compared with the TG data until the kinetic parameters that provide the best agreement between predictions and TG experiments are found. This methodology is efficient and simple, proving good results $[26,27,16]$.

In TG experiments, the mass of the sample inside the experimental oven is very small, on the order of a few milligrams. The inflow rate of gases (i.e. nitrogen or air) into the oven is high compared to the release rate of gaseous products from the degrading solid. Thus, transport effects and thermal gradients inside the solid can be neglected. Under these assumptions and for the mechanism in Eqs. (1-5), the equations governing the solid massloss rate of each species in a TG experiment are be expressed as:

$$
\begin{aligned}
& \frac{\mathrm{dm}_{\mathrm{f}}}{\mathrm{dt}}=-\dot{\omega}_{\mathrm{p}}-\dot{\omega}_{\mathrm{o}} \\
& \frac{\mathrm{dm}_{\beta}}{\mathrm{dt}}=\mathrm{v}_{\beta, \mathrm{p}} \dot{\omega}_{\mathrm{p}}-\dot{\omega}_{\mathrm{p} \beta}-\dot{\omega}_{\mathrm{o} \beta} \\
& \frac{\mathrm{dm}}{\mathrm{dt}}=v_{\mathrm{c}, \mathrm{p} \beta} \dot{\omega}_{\mathrm{p} \beta}+\mathrm{v}_{\mathrm{c}, \mathrm{o}} \dot{\omega}_{\mathrm{o}}+\mathrm{v}_{\mathrm{c}, \mathrm{o} \beta} \dot{\omega}_{\mathrm{o} \beta}-\dot{\omega}_{\mathrm{c}} \\
& \frac{\mathrm{dm}}{\mathrm{dt}}=v_{\mathrm{r}, \mathrm{c}} \dot{\omega}_{\mathrm{c}}
\end{aligned}
$$

where $m_{i}$ is the relative mass of solid species $i$ respect to the initial mass of the sample. To calculate the total mass-loss rate of the sample (m), Eqs. (6-9) are added to give:

$$
\begin{aligned}
& \frac{\mathrm{dm}}{\mathrm{dt}}=\frac{\mathrm{dm}_{\mathrm{f}}}{\mathrm{dt}}+\frac{\mathrm{dm}_{\beta}}{\mathrm{dt}}+\frac{\mathrm{dm}}{\mathrm{c}} \mathrm{dt}+\frac{\mathrm{dm}_{\mathrm{r}}}{\mathrm{dt}}=\left(v_{\beta, \mathrm{p}}-1\right) \dot{\omega}_{\mathrm{p}}+\left(\mathrm{v}_{\mathrm{c}, \mathrm{p} \beta}-1\right) \dot{\omega}_{\mathrm{p} \beta}+\left(\mathrm{v}_{\mathrm{c}, \mathrm{o}}-1\right) \dot{\omega}_{\mathrm{o}}+ \\
& +\left(v_{\mathrm{c}, \mathrm{o} \beta}-1\right) \dot{\omega}_{\mathrm{o} \beta}+\left(\mathrm{v}_{\mathrm{r}, \mathrm{c}}-1\right) \dot{\omega}_{\mathrm{c}}
\end{aligned}
$$


Each of the reaction paths described in Eqs. (1-5) is assumed to have an Arrheniustype reaction rate of the form:

$$
\dot{\omega}_{\mathrm{i}}=\mathrm{A}_{\mathrm{i}} \mathrm{e}^{-\frac{\mathrm{E}_{\mathrm{i}}}{\mathrm{RT}}} \mathrm{m}_{\mathrm{i}}^{\mathrm{n}_{\mathrm{i}}} \mathrm{y}_{\mathrm{O}_{2}}^{\delta}
$$

The initial conditions (Eq. 12), the temperature rise and the oxygen fraction (Eq. 13) are set to imitate the environment in a TG experiment:

$$
\begin{aligned}
& \left\{\begin{array}{l}
\mathrm{m}_{\mathrm{f}}(0)=1 \\
\mathrm{~m}_{\beta}(0)=\mathrm{m}_{\mathrm{c}}(0)=\mathrm{m}_{\mathrm{r}}(0)=0 \\
\mathrm{~T}(0)=\mathrm{T}_{0}
\end{array}\right. \\
& \left\{\begin{array}{l}
\mathrm{y}_{\mathrm{O}_{2}}=0\left(N_{2} \text { atm. }\right) \text { or } \mathrm{y}_{\mathrm{O} 2}=0.23 \text { (air atm.) } \\
\frac{\mathrm{dT}}{\mathrm{dt}}=\mathrm{hr} \equiv \text { constant }
\end{array}\right.
\end{aligned}
$$

Where $\mathrm{h}$ is the heating rate, i.e. the controlled temperature increase inside the oven, typically a constant linear ramp in TG experiments. Following the assumptions mention above, the oxygen concentration $\mathrm{y}_{\mathrm{O}_{2}}$ is set equal to the constant value at the inflow to the oven. The TG experiments of Chao and Wang [13] only reported results in either nitrogen or air atmospheres, so there is not enough information to derive the reaction order for oxygen ( $\delta$ in Eq. 7). Consequently, the exponent $\delta$ is set to 1 for oxidation reactions (i.e. first order reaction) and set to zero in pyrolysis reactions (i.e. independence of oxygen).

The time integration of the mass-loss rates (Eqs. 6-10) together with the initial conditions (Eq. 12) gives the mass of each solid species $\left(\mathrm{m}_{\mathrm{i}}\right)$ at any given time. The solution to this system of ODEs requires a stiff numerical solver. The system contains sixteen unknown kinetic-parameters that are needed in order to compute the reaction rates: four activation energies $E_{i}$, four preexponential factors $A_{i}$, four reaction-order coefficients $n_{i}$, and four stoichiometric yields $v_{j, i}$ (see Table 2 for a complete listing). It is proposed here that these parameters are determined by solving an inverse problem. The inverse problem consists of combining together the mass-loss model and an optimization technique to identify the set of kinetic parameters that best reproduces the mass-loss measured in the TG experiments.

The solution of this inverse problem is too large a task for classical optimization tools. The high dimensionality of the problem (sixteen parameters) produces a large search-space 
and very complicated landscapes for the optimization target, with numerous local maxima and minima. Furthermore, the problem is by definition ill-posed. That is, uniqueness of the solution (the kinetic-parameter set) is not guaranteed because very complex physical processes are being simulated with a quite simple mass-loss model. For these reasons, an efficient multidimensional optimization technique such as genetic algorithms is therefore necessary.

\section{Genetic Algorithms (text reduced 20\%)}

A genetic algorithm (GA) is a heuristic search method that imitates the principles of biological adaptation. It is based upon the mechanics of the Darwinian survival-of-thefittest theory $[29,30]$. In a GA, the candidate solutions represent the individuals in a population that evolve with time in a predetermined environment. In the present application, a candidate solution or individual is a set of values of the kinetic parameters, and the environment consists of the mathematical formulation of the problem and the experimental TG results. The procedure entails the following: an initial population of individuals is randomly generated, then the population undergoes a process of selection such that only those giving the best description of the TG results (the fittest) of every generation are selected to survive. Children for the next generation are bred by reproduction from the parameter-set pool of the parents, plus stochastic mutations. The process is repeated generation after generation until convergence is achieved, i.e. no subsequent improvements occur. The fittest individuals of any population tend to reproduce and survive to the next generation, thus improving successive generations. The method has a stochastic component in the mutation, crossover and selection operations to ensure wide exploration and to avoid becoming trapped in a local extrema.

Compared to classical optimization methods for non-linear problems (i.e. trial and error, linearization, gradient method and Monte Carlo simulation), GAs' advantages include: excellent performance in high-dimensional problems, resistance to becoming trapped in local optima, wide exploration of the parameter space, and elimination of the to evaluate Jacobian matrices and works on non-continuous objective-landscapes. Some of its disadvantages are that it is heuristic in nature, it is inefficient for small problems, and it may not be the fastest method. GAs are capable of quickly finding promising regions of the search space but may take a relatively long time to reach a fine localized solution. GAs have been previously applied to the chemical-kinetics of combustion, specially to 
homogeneous gas-reactions [31, 32, 33], with some papers addressing heterogeneous reactions, like catalytic reactions [34], and polymer curing [35]. GAs and a similar methodology to the one presented here have been applied by the authors to estimate the solid-phase kinetics and physical properties for ?re modeling from bench-scale ?re experiments [36].

In this paper, the GA code used is GAOT [37] in a real-number implementation. Population sizes between 100 and 500 are used. In general, the higher the population is, the larger the explored search-space and convergence occurs in less generations. The adaptation of each parameter-set is measured with a fitness function which is defined here as the inverse of the error between the calculations and the experimental measurement:

$$
\Phi=\left(\int\left|\frac{\mathrm{dm}}{\mathrm{dt}}^{\text {calc }}-\frac{\mathrm{dm}}{\mathrm{dt}}^{\exp }\right| \mathrm{dT}\right)^{-1}+\gamma\left(\int\left|\mathrm{m}^{\text {calc }}-\mathrm{m}^{\exp }\right| \mathrm{dT}\right)^{-1}
$$

The fitness accounts for errors both in the solid mass-loss rate $\mathrm{dm} / \mathrm{dt}$ and in the solid mass $\mathrm{m}$. The constant $\gamma$ represents the relative influence on the fitness of the mass over the influence of the mass-loss rate. Its value is specified by the user's convenience; here it is set to 50 to scale both fitness terms. The integrals in Eq. (14) are numerically evaluated in the range of temperature of the TG experiments (typically from 25 to $600{ }^{\circ} \mathrm{C}$ ). In principle the perfect solution would have an infinite fitness, but in this particular application, and due to noise in the data plus the imperfect fitting, the rough magnitude of the best fitness is 100. The algorithm is stopped when no further improvement of the fitness occurs after several hundreds of generations. Typically, convergence was achieved in less than 1000 generations, requiring a total computer time of less than 10 hours on a 3.0 GHz Pentium PC of the year 2004.

\section{Testing the Methodology against a Benchmark}

Before the above methodology is applied to PU kinetics, its effectiveness is evaluated and tested by applying it to the well-studied problem of the thermal degradation of cellulose. The results are also used to illustrate an exemplar application of GA within this methodology. TG results for cellulose in a nitrogen atmosphere (Fig. 6) were chosen as the best available benchmark to be used in the test because the kinetics is simple and wellknown [21]. The TG data are taken from Grønli et al. [21] (heating rate of $5{ }^{\circ} \mathrm{C} / \mathrm{min}$, curve 
\#7), which is a round-robin study where different laboratories conducted independent TG experiments of the same cellulose and estimated the pyrolysis kinetic-parameters.

The mathematical mass-loss model presented above was modified to fit the cellulose pyrolysis scheme, which is well described by a single-step, first order, pyrolysis reaction:

$$
\begin{aligned}
& \frac{\mathrm{dm}}{\mathrm{dt}}=\frac{\mathrm{dm}}{\mathrm{cel}}{ }_{\mathrm{dt}}+\frac{\mathrm{dm}}{\mathrm{dt}}=\left(\mathrm{v}_{\mathrm{c}, \mathrm{p}}-1\right) \dot{\omega}_{\mathrm{p}} \\
& \dot{\omega}_{\mathrm{p}}=\mathrm{A}_{\mathrm{p}} \mathrm{e}^{-\frac{\mathrm{E}_{\mathrm{p}}}{\mathrm{RT}}} \mathrm{m}_{\text {cel }}
\end{aligned}
$$

The GA methodology was applied in the optimization of the three kinetic parameters of cellulose pyrolysis $\left(A_{p}, E_{p}\right.$ and $\left.v_{c, p}\right)$. Evolution of the best fitness (i.e. performance of the best parameter-set at each generation) is presented in Fig. 4. It can be seen that the improvement is very fast at the beginning and tends toward convergence at a slower pace. Fig. 5 shows the performance of all the individuals attempted by the GA during a typical search in the mass-loss/temperature space. This figure illustrates how initial individuals perform poorly, but as generations proceed, new individuals provide improved mass-loss curves that eventually converge toward the experimental results.

The best set of kinetic-parameters found is reported Table 1 and its performance simulating the TG experiments is shown Fig. 6. It is seen that the simulated TG curve fits the experimental curve over the entire temperature range. Moreover, the parameters estimated are in excellent agreement with those determined in the benchmark study through more traditional analytical methods [21]. Grønli et al. reported significant scatter among the measured mass-loss curves provided by the different laboratories due to experimental variations in sample size, heating rate, thermal lag and the instruments used. This experimental scatter subsequently induced variations in the kinetic parameters determined by the different laboratories. These variations are reported in Table 1 as TG scatter. The differences between the benchmark values and the GA-estimated values are also presented in Table 1. It is seen that these differences are significantly lower than the induced variations due to TG scatter. This contrast suggests that with respect to the analytical method used in the benchmark, the differences introduced by the application of GAs to determine kinetic parameters are significantly lower than those associated to the experimental error in TG. 


\section{Application to the Kinetics of Polyurethane Foam}

In this section the proposed methodology is applied to determine the kinetic parameters of PU using the five-step mechanism in Eqs. (1-5). The TG measurements of Chao and Wang [13] for flexible PU foam are used to obtain the kinetic parameters. Chao and Wang used commercially available non-fire retarded flexible polyurethane foam. Their tests were conducted at heating rates of 5,10 , and $20^{\circ} \mathrm{C} / \mathrm{min}$ and in nitrogen and air. Tests in nitrogen give information only on the pyrolysis paths (Fig. 2), and in air on both the pyrolysis and oxidation paths together (Fig. 3).

Analysis of available experimental data on the smoldering behavior of PU [38, 39] shows that the temperature variation rate (i.e. heating rate) of the virgin foam produced by the propagating front ranges between approximately 1 and $150{ }^{\circ} \mathrm{C} / \mathrm{min}$, with an average about $50{ }^{\circ} \mathrm{C} / \mathrm{min}$. For this reason, the heating rate of $20^{\circ} \mathrm{C} / \mathrm{min}$ (the highest available from the TG data) was chosen to obtain the kinetic parameters. The other two heating rates (5 and 10 ${ }^{\circ} \mathrm{C} / \mathrm{min}$ ) were used as blind predictions for validation purposes and to test the suitability of the parameters for extrapolation to different heating rates.

A comparison of the experimental and modeled TG curves, using the optimal parameters determined as described above, is presented in Figs. 2 and 3. The fitness was evaluated applying Eq. (14) simultaneously to both nitrogen and air atmosphere results. It is seen that the five-step mechanism captures the position and magnitude of the peaks in all of the mass-loss curves, demonstrating the capabilities of the mechanism at different heating rates and oxygen concentrations. Numerical values of all the kinetic parameters are given in Table 2 .

The role of each reaction in the simulated TG results are explored in Figs. 7 and 8, where each of the calculated reaction rates $\dot{\omega}_{i}$ are shown at a heating rate of $20{ }^{\circ} \mathrm{C} / \mathrm{min}$. In nitrogen atmosphere (Fig. 7), the virgin foam pyrolysis produces the first peak shown in the TG mass-loss of Fig. 2, and the $\beta$-foam pyrolysis produces the second peak. Overlapping of the two pyrolysis paths occurs between 290 and $320^{\circ} \mathrm{C}$. Evidently, in the model no oxidation takes place in nitrogen atmosphere. In air (Fig. 8), the competing pyrolysis and oxidation reactions of the virgin foam overlap completely, producing the first peak in the TG mass-loss rate shown in Fig. 3 between 200 and $330{ }^{\circ} \mathrm{C}$. In air, most of the virgin foam is pyrolyzed rather than oxidized, and the $\beta$-foam pyrolysis has low intensity. Similarly, the competing pyrolysis and oxidation reactions of the $\beta$-foam overlap completely, producing the second peak in the TG mass-loss rate of Fig. 3 between 270 and $350{ }^{\circ} \mathrm{C}$. Fig. 8 shows that in air, 
most of the virgin foam is pyrolyzed rather than oxidized, whereas most of the $\beta$-foam is oxidized rather than pyrolyzed. The oxidation of the char takes place between $300{ }^{\circ} \mathrm{C}$ and $420{ }^{\circ} \mathrm{C}$.

Values of the stoichiometric parameters in Table 2 can also be used to interpret the mass-yields of species and gases. Pyrolysis of the virgin foam would yield roughly one-third as gas, whereas pyrolysis of the $\beta$-foam would yield little char and thus most of it becomes gas. Oxidation of the virgin foam and the $\beta$-foam would yield roughly half gas and haft char, whereas char oxidation would have a small yield of solid residue.

The uniqueness of the solution (i.e. the kinetic-parameter set) is always a concern in inverse problems. To resolve the issue, two approaches are followed here; one is to verify that the parameters are applicable at the other two heating rates (blind predictions); and the other is to determine the confidence limits of the value for each parameter are listed in Table 2 by expressing them as the value of the fittest individual accompanied by the range of values of other well-fitted individuals (top 10\% of the end population). The estimated values for the pre-exponential factors and the activation energies are considerably sensitive to the optimization conditions, and thus their wide confidence limits. This sensitivity is expected [21], although it is found that significant differences in the values of the kinetic parameters yield small differences in the simulated TG curves. Also, the parameters show interdependence; the upper bound for the pre-exponentials correspond with the upper bound of the activation energies, and the same way with the lower bounds. Lower values of the pre-exponential factor are compensated for by slightly lower values of the activation energy. The results show that the interdependence is particularly strong and linear (fit goodness $\mathrm{R}^{2}>0.97$ ) in the cases of the foam pyrolysis and the char oxidation. Their respective trends inside the ranges shown in Table 2 are of the form:

$$
\begin{aligned}
& \log _{10}\left(\mathrm{~A}_{\mathrm{p}}\right)=-2.40+0.093 \mathrm{E}_{\mathrm{p}} \\
& \log _{10}\left(\mathrm{~A}_{\mathrm{c}}\right)=-1.56+0.083 \mathrm{E}_{\mathrm{c}}
\end{aligned}
$$

Where $A_{i}$ is expressed in $[1 / \mathrm{s}]$ and $E_{i}$ in $[\mathrm{kJ} / \mathrm{mol}]$. This interdependence of the values is called "kinetic compensation effect" and has been long-observed to occur in the estimation of kinetic parameters from TG experiments [40, 41]. This linear interdependence results from the interaction between the mathematical nature of the Arrhenius-reaction rates and physicochemical and experimental factors [41]. 
The five-step mechanism does not capture the small mass-loss that occurs in air at temperatures between 450 and $600{ }^{\circ} \mathrm{C}$. This secondary oxidation reaction (also sometimes referred to as secondary char oxidation) was not included in the mechanism because it occurs at high temperature and is of little consequence to smolder propagation [42, 43]. Moreover, secondary char oxidation consumes one-order of magnitude more mass of oxygen per mass of reactant than the first oxidation [43] so its effect on the TG experiments might be controlled by oxygen transport rather than by kinetics, in which case it would not be well-described by our mass-loss model (Eq. 5 and 6).

\section{Application of the Kinetic Mechanism to Smoldering Combustion}

One-dimensional propagation of smoldering combustion is classified as either forward or opposed (Fig. 8). In forward smolder, the reaction front moves in the same direction as the oxidizer flow, while in opposed smolder the front moves in the opposite direction to the oxidizer. These propagation modes differ from each other by the heat and mass transfer characteristics, and thus they have essential differences in the role played by each reaction [44]. Conventional models of PU smoldering use different kinetic schemes depending on the propagation mode. Forward smolder is generally described as having both the pyrolysis and oxidation reactions independently included in the mechanism [18, $45,46,47]$, whereas in opposed propagation they are lumped together in a global single reaction $[17,48,49,50,51]$. To date, no study has attempted to describe both forward and opposed smolder-propagation with the same kinetic mechanism and the same kinetic parameters. Hence, the objective of this section is to verify with a simple species model that the kinetics extracted from TG experiments can be applied to smoldering combustion of PU in both forward and opposed configurations.

The simple species model consists of the species conservation equations of a smolderfront propagating though PU, assuming one-dimensional and steady state conditions. The energy equation is not solved for but replaced with a prescribed temperature distribution ahead of and behind the smoldering front. The smolder velocity is prescribed as well. Ahead of the smoldering front, the temperature distribution is obtained by fitting its theoretical expression [52] with previous experimental results for both opposed and forward smolder propagation [38, 39]. Behind the smolder front, the temperature is assumed constant and equal to the maximum smolder temperature in the experiments. This condition implies the assumption of no heat losses. Air is forced at the inlet and 
considered to flow through the porous material at constant velocity. It is assumed that the gas and solid phases are in thermal equilibrium. In the gas phase, only the species conservation for oxygen is solved, and it considers both convective transport and consumption by the oxidation reactions. In the solid phase, consumption and production of the four solid species by all five reactions is considered. Time derivatives are converted into spatial derivatives by anchoring the system of coordinates to the steady-state propagating front. The corresponding boundary value problem is given in non-dimensional form by the following system of ODEs.

Mass fraction of oxygen in the gas phase:

$$
\frac{d y_{\mathrm{O}_{2}}}{\mathrm{~d} \xi}=\frac{\rho_{\mathrm{s}}}{\rho_{\mathrm{g}}} \frac{\mathrm{L}}{\tau\left(\mathrm{u}_{\mathrm{sml}}+\mathrm{u}_{\mathrm{g}}\right)} \sum_{\mathrm{i}} v_{\mathrm{O}_{2}, \mathrm{i}} \dot{\theta}_{\mathrm{i}}=\frac{\rho_{\mathrm{s}}}{\rho_{\mathrm{g}}} \frac{1}{\mathrm{Da}_{\mathrm{g}}}\left(v_{\mathrm{O}_{2}, \mathrm{\theta}} \dot{\theta}_{\mathrm{o}}+v_{\mathrm{O}_{2}, \mathrm{o} \beta} \dot{\theta}_{\mathrm{o} \beta}+v_{\mathrm{O}_{2}, \mathrm{c}} \dot{\theta}_{\mathrm{c}}\right)
$$

Mass fraction of solid species $\mathrm{j}$ :

$$
\frac{\mathrm{dm}}{\mathrm{d} \xi}=\frac{\mathrm{L}}{\tau \mathrm{u}_{\mathrm{sml}}} \sum_{\mathrm{i}} \mathrm{v}_{\mathrm{j}, \mathrm{i}} \dot{\theta}_{\mathrm{i}}=\frac{1}{\mathrm{Da}_{\mathrm{s}}} \sum_{\mathrm{i}} \mathrm{v}_{\mathrm{j}, \mathrm{i}} \dot{\theta}_{\mathrm{i}}
$$

Where $\xi$ is the non-dimensional spatial variable, $\dot{\theta}_{\mathrm{i}}=\tau \mathrm{A}_{\mathrm{i}} \mathrm{e}^{-\frac{\mathrm{E}_{\mathrm{i}}}{\mathrm{RT}}} \mathrm{m}_{\mathrm{i}}{ }^{\mathrm{n}_{\mathrm{i}}} \mathrm{y}_{\mathrm{O}_{2}}^{\delta}$ is the nondimensional reaction-rate, the Damkohler number for each phase is defined as $\mathrm{Da}=\mathrm{L} / \tau \mathrm{u}$, and $\mathrm{L}$ is the characteristic thickness of the smolder front. The smolder-front propagation velocity $u_{\mathrm{sml}}$ and the gas velocity $\mathrm{u}_{\mathrm{g}}$ are input parameters to the model, and their values are taken from the literature (Table 3). The characteristic time $\tau$ is selected such that it scales the order of magnitude of $\dot{\theta}_{\mathrm{i}}$ to be around 1 .

The boundary conditions and the temperature profile for each propagation mode are specified to correspond to the conditions illustrated in Fig. 9. For forward propagation:

$$
\begin{aligned}
& \left\{\begin{array}{l}
\mathrm{y}_{\mathrm{O}_{2}}(\xi=-\infty)=0.23 \\
\mathrm{~m}_{\mathrm{f}}(\xi=\infty)=1 \\
\mathrm{~m}_{\beta}(\xi=\infty)=\mathrm{m}_{\mathrm{c}}(\xi=\infty)=\mathrm{m}_{\mathrm{c}}(\xi=\infty)=0
\end{array}\right. \\
& \Pi_{\text {fwd }}= \begin{cases}1 & \xi \leq 0 \\
\exp \left(-\alpha_{\text {fwd }} \xi\right) & \xi>0\end{cases}
\end{aligned}
$$

and for opposed propagation: 


$$
\begin{aligned}
& \left\{\begin{array}{l}
\mathrm{y}_{\mathrm{O}_{2}}(\xi=-\infty)=0.23 \\
\mathrm{~m}_{\mathrm{f}}(\xi=-\infty)=1 \\
\mathrm{~m}_{\beta}(\xi=-\infty)=\mathrm{m}_{\mathrm{c}}(\xi=-\infty)=\mathrm{m}_{\mathrm{r}}(\xi=-\infty)=0
\end{array}\right. \\
& \Pi_{\mathrm{opp}}= \begin{cases}\exp \left(\alpha_{\mathrm{opp}} \xi\right) & \xi<0 \\
1 & \xi \geq 0\end{cases}
\end{aligned}
$$

where the nondimensional temperature is defined as $\Pi=(\mathrm{T}-300) /\left(\mathrm{T}_{\mathrm{sml}}-300\right)$, and $\alpha=\mathrm{L} / \mathrm{L}_{\mathrm{t}}$ is the ratio of the smolder-front thickness to the thermal thickness, defined for each propagation mode.

To apply Eq. (19) it is necessary to know first the mass consumptions of oxygen for the oxidation reactions in Eqs. (3-5), namely $v_{\mathrm{O}_{2}, \mathrm{o}}, \mathrm{v}_{\mathrm{O}_{2}, \mathrm{o} \beta}$ and $\mathrm{v}_{\mathrm{O}_{2}, \mathrm{c}}$. These values are not available in the literature and thus they were determined based on the modeling results. First, for simplicity it is assumed than $v_{\mathrm{O}_{2}, \mathrm{o}}$ and $\mathrm{v}_{\mathrm{O}_{2}, \mathrm{o} \beta}$ are equal. Then, based on the numerical predictions, the selected values were those resulting in the oxidation reactions occurring near the location of the peak temperature. The final values of these parameters (listed in Table 3) are in relatively good agreement with previously reported values for a three-step mechanism [16]. The other parameters used in the model, given also in Table 3, are either extracted from previous studies of PU smoldering combustion in microgravity, or selected to scale the nondimensional variable to have an order of magnitude of 1 .

\section{Results and Discussion}

The species model predicts the spatial distribution of the different species in the vicinity of the front, and the role of each of the five reactions in this structure. Due to the steady-state assumption, these profiles propagate at the same velocity as the smoldering front $\mathrm{u}_{\mathrm{sml}}$. Experimental observations of reaction rates and species concentrations in smoldering combustion are very limited and only inferences from temperature measurements, ultrasound imaging and inspection of burned samples can be used. Thus, the model predictions can only be compared phenomenologically to experimental observations.

Results of the reaction rates and species mass-fractions are shown in Fig. 10 (forward) and Fig. 11 (opposed) for the conditions in Table 3. It is seen that the model predicts that 
both fronts consume all the incoming oxygen, as inferred from experiments [1, 38, 46, 49]. However, considerable differences in the front structure can be observed between the two propagation modes.

In forward smoldering propagation (Fig. 10), the oxidation and the pyrolysis reactions form two distinct propagating fronts: the pyrolysis front arriving first to the virgin foam and then followed by the oxidation front. This is in agreement with experimental measurement in forward smolder propagation [39, 46] where two propagating fronts are observed in the temperature profiles. According to the species model, forward smolder results in virtually no oxidation of the virgin foam, as all of it is converted to $\beta$-foam. The $\beta$ foam is subsequently consumed by both the pyrolysis and oxidation reactions. Also, there is a small fraction of char left behind the front. This is because the assumption of no heat losses produces an upstream region of high temperature where oxygen concentration is also high, so the char oxidation step is vigorous, and all the char is converted to residue. This vigorous char oxidation, typical of forward propagation, has been identified as a precursor to the transition from smoldering to flaming combustion, because the transition has strong links with the highly exothermic char and residue (secondary char) oxidation reactions [53].

In contrast, the oxidation and the pyrolysis reactions in opposed smoldering propagation (Fig. 11) overlap to form a single propagating front. This is also in agreement with experimental observations in opposed propagation, where a single propagating front is observed in the temperature profiles [38, 49]. According to the species model, the degradation of the virgin foam occurs via both pyrolysis and oxidation reactions but is dominated by the former. The $\beta$-foam is mainly consumed by the oxidation path rather than by its competing pyrolysis path. Opposed smoldering combustion results in a higher char fraction left behind the smolder front than in the forward mode, also in agreement with experimental observations $[38,49]$. This is due to the starvation of oxygen occurring before the char oxidation is complete.

\section{Concluding Remarks}

The use of a genetic algorithm to determine solid-phase pyrolysis and oxidative kinetics by correlating a reaction mechanism of thermal and oxidative degradation with thermogravimetric data has been demonstrated. It is found that the five-step mechanism and the calculated kinetic-parameters work well for the prediction of thermogravimetric 
data at different heating rates and gas atmospheres. Moreover, the mechanism and its parameters are able to predict the species structure of a smolder-front. Using the kinetics developed in this work, a species model of the PU kinetics in a smoldering front shows that it is possible to predict (at least phenomenologically) the experimental observations of the species distributions in both opposed and forward smolder. This result is very useful in the development of numerical models of smoldering combustion, especially in multidimensional simulations where distinction between forward and opposed modes is no longer rigorous. A fully detailed model of forward and opposed smoldering ignition and propagation including the kinetics from this work plus heat, mass and momentum transports in porous media is presented elsewhere $[54,55]$.

The methodology proposed here can be applied to other materials, or to estimate other not readily available material-properties, such as enthalpies of reaction from calorimetry experiments. With quantified enthalpies of reaction, it will be feasible to solve the energy conservation equation of the smolder front, avoiding the use of a prescribed temperature distribution or calibration of the results. This would allow exploring in more detail the role played by each reaction and its accurate distribution inside the smolder front.

\section{Acknowledgments}

This work was supported by the National Aeronautics and Space Administration (USA) under grant NAG32026. Thanks are given to Prof. C.Y.H. Chao (Hong-Kong Univ. of Science and Tech.), Prof. M.J. Antal (Univ. Hawaii) and Prof. G. Varhegyi (Hungarian Academy of Sciences) for providing the TG data. The authors would like to acknowledge the assistance of Ms. J.B. Herren (UC Berkeley) running the genetic algorithms, and the comments provided by Dr. E.M. Kallman (UC Berkeley), Dr. M. Mikofski (UC Berkeley), Dr. M. Belloc (Univ. of Siena) and Dr. R. Abergel (UC Berkeley).

\section{References}

1. T.J. Ohlemiller, 1985, Modeling of Smoldering Combustion Propagation, Progress in Energy and Combustion Science 11, pp. 277-310.

2. T.J. Ohlemiller, 2002, Smoldering Combustion, SFPE Handbook of Fire Protection Engineering (3rd Ed), Chapter 2, pp. 200-210. 
3. J.R. Hall, 2004, The Smoking-Material Fire Problem, Fire Analysis and Research Division of The National Fire Protection Association, Quincy, MA (USA). November 2004.

4. NASA, 2003, Research Needs in Fire Safety for the Human Exploration and Utilization of Space: Proceedings and Research Plan, NASA CP-2003-212103 (Ed. G.A. Ruff).

5. T. Paulos, F. Issacci, I. Catton, G.E. Apostolakis, 1994, Proceedings of $2^{\text {nd }}$ Probabilistic Safety Assessment and Management Conference (Ed. G.E Apostolakis), San Diego, CA (USA), Vol. 3, pp. 099-15-099-20.

6. J. Oberg, 2001, Star-Crossed Orbits: Inside the U.S.-Russian Space Alliance, McGrawHill, New York (USA).

7. S.V. Levchik, E.D. Weil, 2004, Thermal decomposition, combustion and fire-retardancy of polyurethanes-a review of the recent literature, Polymer International 53, pp.15851610.

8. S. Brereton, R.M. Laing, 1992, Analysis of injury and death from burning upholstered furniture, New Zealand Medical Journal 105, pp. 429-32.

9. M. Ravey, E.M. Pearce, 1997, Flexible polyurethane foam. I. Thermal decomposition of a polyether-based, water-blown commercial type of flexible polyurethane foam, Journal of Applied Polymer Science 63 (1), pp. 47-74.

10.R. Font, A. Fullana, J.A. Caballero, J. Candela, A. García, 2001, Pyrolysis study of polyurethane, Journal of Analytical and Applied Pyrolysis 58-59 (1), pp. 63-77.

11.I. Auerbach, 1989, Evaluation of kinetic-parameters appropriate for modeling urethane foam insulation performance, Journal of Thermal Analysis 35, pp. 1629-1641.

12.R. Bilbao, J.F. Mastral, J. Ceamanos and M.E. Aldea, 1996, Kinetics of the thermal decomposition of polyurethane foams in nitrogen and air atmospheres, Journal of Analytical and Applied Pyrolysis 37, pp. 69-82.

13.C.Y.H. Chao, J.H. Wang, 2001, Comparison of the Thermal Decomposition Behavior of a Non-Fire Retarded and a Fire Retarded Flexible Polyurethane Foam, Journal of Fire Science 19, pp. 137-155.

14.S.V. Leach, J.L. Ellzey, O.A. Ezekoye, 1997, A numerical study of reverse smoldering, Combustion Science and Technology 130 (1-6), pp. 247-267. 
15.S.V. Leach, G. Rein, J.L. Ellzey, O.A. Ezekoye, J.L. Torero, 2000, Kinetic and fuel property effects on forward smoldering combustion, Combustion and Flame 120 (3), pp. 346-358.

16. G. Rein, A. Bar-Ilan, A.C. Fernandez-Pello, J.L. Ellzey, J.L. Torero, D.L. Urban, 2005, Modeling of One-Dimensional Smoldering of Polyurethane in Microgravity Conditions, Proceedings of the Combustion Institute 30 (2), pp. 2327-2334.

17.S.S. Dosanjh, P.J. Pagni, A.C. Fernandez-Pello, 1987, Forced cocurrent smoldering combustion, Combustion and Flame 68 (2), pp. 131-142

18.S.S. Dosanjh, P.J Pagni, 1987, Forced countercurrent smoldering combustion, Proceedings of the 1987 ASME/JSME Thermal Engineering Joint Conference (Ed. P.J. Marto and I. Tanasawa), pp. 165-173.

19. Dr. M. Mikofski, 2004, personal communications, University of California at Berkeley.

20.J.A. Conesa, A. Marcilla, J.A. Caballero, R. Font, 2001, Comments on the validity and utility of the different methods for kinetic analysis of thermogravimetric data, Journal of Analytical and Applied Pyrolysis 58-59, pp. 617-633.

21.M. Grønli, M.J. Antal, G. Varhegyi, 1999, A round-robin study of cellulose pyrolysis kinetics by thermogravimetry, Industrial and Engineering Chemistry Research 38, pp. 2238-2244.

22.H.E. Kissinger, 1957, Reaction kinetics in differential thermal analysis, Analytical Chemistry 29 (11), pp. 1702-1706.

23. M.L. Kelley, D.A. Schult, 2006, Modeling extinction in forced opposed flow smolder, Combustion Theory and Modelling 10 (1), pp. 133-143.

24.F.E. Rogers, T.J. Ohlemiller, 1981, Pyrolysis kinetics of a polyurethane foam by thermogravimetry: a general kinetic model, Journal of Macromolecular Science A15 (1), pp.169-185.

25.R.R. Mahajan, P.S. Makashir, E.M. Kurian, 2000, Thermal and Spectroscopic Studies on High Density Polyurethane Foam, Journal of Polymer Materials 17, pp.47-52.

26. C.L. Beyler, Marcelo M. Hirschler, 2001, Thermal Decomposition of Polymers, SFPE Handbook of Fire Protection Engineering (3rd Ed), Section 1, Chapter 7, pp. 1-110. 
27. C. Branca, C. Di Blasi, A. Casu, V. Morone, C. Costa, 2003, Reaction kinetics and morphological changes of a rigid polyurethane foam during combustion. Thermochimica Acta 399, pp. 127-137.

28.V. Mamleev, S. Bourbigot, M. Le Bras, S. Duquesne, J. Sestak, 2000, Modeling of nonisothermal kinetics in thermogravimetry, Physical Chemistry Chemical Physics 2, pp. 4796-4803.

29.D. Goldberg, 1989, Genetic Algorithms: In Search, Optimization and Machine Learning, Addison-Wesley.

30.J.A. Foster, 2001, Evolutionary Computations, Nature 2001 Vol. 2, pp. 428-436.

31.J.T. Alander, A. Autere, J. Mäntykoski, K.I. Keskinen, 1994. Distributed genetic algorithm for fitting of model parameters of chemical reaction kinetics. Proceedings of the $2^{\text {nd }}$ Finnish Workshop on Genetic Algorithms and their Applications, Report 94-2, 16-18, pp. 115-126.

32.W. Polifke, W. Geng, K. Döbbeling, 1998, Optimization of Rate Coefficients for Simplified Reaction Mechanisms with Genetic Algorithms. Combustion and Flame 113, pp. 119-134.

33.L. Elliott, D.B. Ingham, A.G. Kyne, N.S. Mera, M. Pourkashanian, and C.W. Wilson, 2004, Genetic Algorithms for Optimisation of Chemical Kinetics Reaction Mechanisms, Progress in Energy and Combustion Science 30, pp. 297-328.

34.D. Wolf, R. Moros, 1997, Estimating rate constants of heterogeneous catalytic reactions without supposion of rate determining surface steps - an application of a genetic algorithm. Chemical Engineering Science 52, pp. 1189-1199.

35.S. Garcia, 1999. Experimental Design Optimization and Thermophysical Parameter Estimation of Composite Materials Using Genetic Algorithms. PhD Thesis, Virginia Polytechnic Institute (and Universite de Nantes).

36. C. Lautenberger, G. Rein, C. Fernandez-Pello, 2006, The application of a genetic algorithm to estimate material properties for ?re modeling from bench-scale ?re test data. Fire Safety Journal (in press).

37.C.R. Houck, J.A. Joines, M.G. Kay, 1995, GAOT: A Genetic Algorithm for Function Optimization: a Matlab Implementation, Report NCSU-IE TR 95-09. http://www.ie.ncsu.edu. 
38. A. Bar-Ilan, G. Rein, D.C. Walther, A.C. Fernandez-Pello, J.L. Torero, D.L. Urban, 2004, The effect of buoyancy on opposed smoldering, Combustion Science and Technology 176, 2027-2055.

39. A. Bar-Ilan, G. Rein, A.C. Fernandez-Pello, J.L. Torero, D.L. Urban, 2004, Forced Forward Smoldering Experiments in Microgravity, Experimental Thermal and Fluid Science 28, pp. 743-751.

40.E. Chornet, C. Roy, 1980, Compensation Effect in the Thermal Decomposition of Cellulosic Materials. Thermochimica Acta 35, pp. 389-393.

41.N. Koga, 1995, A review of the mutual dependence of Arrhenius parameters evaluated by the thermoanalytical study of solid-state reactions: The kinetic compensation effect, Thermochimica Acta 244, pp. 1-20.

42.F.E. Rogers, T.J. Ohlemiller, 1980, Smolder characteristic of flexible polyurethane foams, Journal of Fire and Flammability 11 (1), pp. 32-44.

43. C.Y.H. Chao, J.H. Wang, 2001, Transition from smoldering to flaming combustion of horizontally oriented flexible polyurethane foam with natural convection, Combustion and Flame 127, pp. 2252-2264.

44.T.J. Ohlemiller, D.A. Lucca, 1983, An experimental comparison of forward and reverse smolder propagation in permeable fuel beds, Combustion and Flame 54 (1-3), pp. 131147.

45.J. Buckmaster, D. Lozinski, 1996, An elementary discussion of forward smoldering, Combustion and Flame 104 (3), pp. 300-310.

46.J.L. Torero, A.C. Fernandez-Pello, 1996, Forward smolder of polyurethane foam in forced air flow, Combustion and Flame 106, pp. 89-109.

47.D.A. Schult, B.J. Matkowsky, V.A. Volpert, A.C. Fernandez-Pello, 1996, Forced forward smolder combustion, Combustion and Flame 104 (1-2), pp. 1-26.

48.D. Lozinski, J. Buckmaster, 1995, Quenching of reverse smolder, Combustion and Flame 102 (1-2), pp. 87-100.

49.J.L. Torero, A.C. Fernandez-Pello, M. Kitano, 1993, Opposed forced flow smoldering of polyurethane foam, Combustion Science and Technology 91, pp. 95-117. 
50.T.J. Ohlemiller, J. Bellan, F. Rogers, 1979, A model of smoldering combustion applied to flexible polyurethane foams, Combustion and Flame Vol. 36, pp. 197-215.

51.D.A. Schult, B.J. Matkowsky, V.A. Volpert, A.C. Fernandez-Pello, 1995, Propagation and extinction of forced opposed flow smolder waves, Combustion and Flame 101 (4), pp. 471-490.

52.M.A. Decker, D.A. Schult, 2004, Dynamics of smoulder waves near extinction, Combustion Theory and Modeling 8 (3), pp. 491-512.

53. O. Putzeys, A. Bar-Ilan, G. Rein, A.C. Fernandez-Pello, D.L. Urban. "The role of secondary char oxidation in the transition from smoldering to flaming", Proceedings of the Combustion Institute 31, (in press) 2006.

54.G. Rein, A.C. Fernandez-Pello, D.L. Urban, "Computational Model of Forward and Opposed Smoldering Combustion in Microgravity", Proceedings of the Combustion Institute 31, (in press) 2006.

55.G. Rein, "Computational Model of Forward and Opposed Smoldering Combustion with Improved Chemical Kinetics", PhD Thesis, The University o California at Berkeley, 2005. Available at http://repositories.cdlib.org/cpl/fs/ReinPhD05. 


\section{Tables}

Table 1. Kinetic and stoichiometric parameters for cellulose and comparison with TG benchmark (curve \#7 in [21]).

\begin{tabular}{cc|cc|cc}
\hline Parameter & GA & $\begin{array}{c}\text { TG } \\
\text { Benchmark }\end{array}$ & $\begin{array}{c}\text { TG } \\
\text { Scatter }\end{array}$ & $\begin{array}{c}\text { GA-TG } \\
\text { Difference }\end{array}$ & Units \\
\hline $\mathrm{E}_{\mathrm{p}}$ & 236 & 241 & $12 \%$ & $2 \%$ & $\mathrm{~kJ} / \mathrm{mol}$ \\
$\log _{10}\left(\mathrm{~A}_{\mathrm{p}}\right)$ & 18.4 & 18.8 & $17 \%$ & $2 \%$ & $\log _{10}(1 / \mathrm{s})$ \\
$\mathrm{v}_{\mathrm{c}, \mathrm{p}}$ & 0.050 & 0.052 & $90 \%$ & $4 \%$ & - \\
\hline
\end{tabular}

Table 2. Kinetic and stoichiometric parameters for PU foam estimated using GA.

\begin{tabular}{cccc}
\hline Parameter & Best & Range & Units \\
\hline $\mathrm{E}_{\mathrm{p}}$ & 148 & {$[136,160]$} & $\mathrm{kJ} / \mathrm{mol}$ \\
$\log _{10}\left(\mathrm{~A}_{\mathrm{p}}\right)$ & 11.3 & {$[10.4,12.5]$} & $\log _{10}(1 / \mathrm{s})$ \\
$\mathrm{n}_{\mathrm{p}}$ & 0.21 & {$[0.13,0.31]$} & - \\
$\mathrm{v}_{\beta, \mathrm{p}}$ & 0.70 & {$[0.69,0.71]$} & $\mathrm{kg} / \mathrm{kg}$ \\
$\mathrm{E}_{\mathrm{p} \beta}$ & 124 & {$[121,127]$} & $\mathrm{kJ} / \mathrm{mol}$ \\
$\log _{10}\left(\mathrm{~A}_{\mathrm{p} \beta}\right)$ & 8.2 & {$[7.8,8.5]$} & $\log _{10}(1 / \mathrm{s})$ \\
$\mathrm{n}_{\mathrm{p} \beta}$ & 1.14 & {$[1.12,1.18]$} & - \\
$\mathrm{v}_{\mathrm{c}, \mathrm{p} \beta}$ & 0.05 & {$[0.04,0.06]$} & $\mathrm{kg} / \mathrm{kg}$ \\
$\mathrm{E}_{\mathrm{o}}$ & 194 & {$[161,220]$} & $\mathrm{kJ} / \mathrm{mol}$ \\
$\log _{10}\left(\mathrm{~A}_{\mathrm{o}}\right)$ & 15.4 & {$[12.6,16.7]$} & $\log _{10}(1 / \mathrm{s})$ \\
$\mathrm{n}_{\mathrm{o}}$ & 0.52 & {$[0.47,0.69]$} & - \\
$\mathrm{v}_{\mathrm{c}, \mathrm{o}}$ & 0.57 & {$[0.55,0.57]$} & $\mathrm{kg} / \mathrm{kg}$ \\
$\mathrm{E}_{\mathrm{o} \beta}$ & 194 & {$[161,220]$} & $\mathrm{kJ} / \mathrm{mol}$ \\
$\log _{10}\left(\mathrm{~A}_{\mathrm{o} \beta}\right)$ & 15.4 & {$[12.6,16.7]$} & $\log _{10}(1 / \mathrm{s})$ \\
$\mathrm{n}_{\mathrm{o} \beta}$ & 0.52 & {$[0.47,0.69]$} & - \\
$\mathrm{v}_{\mathrm{c}, \mathrm{o} \beta}$ & 0.57 & {$[0.55,0.57]$} & $\mathrm{kg} / \mathrm{kg}$ \\
$\mathrm{E}_{\mathrm{c}}$ & 201 & {$[193,220]$} & $\mathrm{kJ} / \mathrm{mol}$ \\
$\log _{10}\left(\mathrm{~A}_{\mathrm{c}}\right)$ & 15.2 & {$[14.5,16.7]$} & $\log 10(1 / \mathrm{s})$ \\
$\mathrm{n}_{\mathrm{c}}$ & 1.23 & {$[1.10,1.49]$} & - \\
$\mathrm{v}_{\mathrm{r}, \mathrm{c}}$ & 0.23 & {$[0.21,0.25]$} & $\mathrm{kg} / \mathrm{kg}$ \\
\hline & & &
\end{tabular}


Table 3. Scaling variables and parameters for the species model

\begin{tabular}{cccc}
\hline Parameter & Value & Units & Reference \\
\hline $\mathrm{u}_{\mathrm{g}}$ & 3 & $\mathrm{~mm} / \mathrm{s}$ & {$[38,39]$} \\
$\mathrm{T}_{\mathrm{sml}}$ (forward) & 680 & $\mathrm{~K}$ & {$[39]$} \\
$\mathrm{u}_{\mathrm{sml}}$ (forward) & -0.15 & $\mathrm{~mm} / \mathrm{s}$ & {$[39]$} \\
$\alpha_{\text {fwd }}$ & 1.25 & - & {$[39]$} \\
$\mathrm{T}_{\mathrm{sml}}$ (opposed) & 690 & $\mathrm{~K}$ & {$[38]$} \\
$\mathrm{u}_{\mathrm{sml}}$ (opposed) & 0.19 & $\mathrm{~mm} / \mathrm{s}$ & {$[38]$} \\
$\alpha_{\text {opp }}$ & 0.71 & - & {$[38]$} \\
$\mathrm{v}_{\mathrm{O}_{2}, \mathrm{o}}$ and $\mathrm{v}_{\mathrm{O}_{2}, \mathrm{o} \beta}$ & 0.08 & - & \\
$v_{\mathrm{O}_{2}, \mathrm{c}}$ & 0.30 & - & \\
$\rho_{\mathrm{s}}$ & 26.4 & $\mathrm{Kg} / \mathrm{m}^{3}$ & {$[13]$} \\
$\tau$ & 10.9 & $\mathrm{~s}$ & scaling \\
$\mathrm{L}$ & 20 & $\mathrm{~mm}$ & scaling \\
\hline
\end{tabular}




\section{Figure Captions}

Figure 1. Scan Electron Microscopy imaging of polyurethane foam [19]: (a) virgin foam; (b) pyrolyzed foam; and (c) smoldered char.

Figure 2. Polyurethane foam mass-loss kinetics in nitrogen as a function of temperature for three heating rates, a) solid mass; b) mass-loss rate. Marks: experimental [13]; Lines: calculations.

Figure 3. Polyurethane foam mass-loss kinetics in air as a function of temperature for three heating rates, a) solid mass; b) mass-loss rate. Marks: experimental [13]; Lines: calculations.

Figure 4. Evolution with generations of the best fitness found by the genetic algorithm during a typical search for cellulose kinetics.

Figure 5. Mass-loss behavior of all the individuals attempted by the genetic algorithm during a typical search for cellulose kinetics. Circles are the experimental results.

Figure 6. Cellulose mass-loss rate in nitrogen as a function of temperature for a heating rate of $5 \mathbb{C} / \mathrm{min}$. Marks are experiments [21]; Lines are numerical.

Figure 7. Simulated polyurethane mass-loss pyrolysis reaction-rates $\dot{\omega}_{\mathrm{i}}$ in nitrogen atmosphere, as a function of temperature for $20 \mathbb{C} / \mathrm{min}$ heating-rate.

Figure 8. Simulated polyurethane mass-loss reaction-rates $\dot{\omega}_{i}$ in air atmosphere for; a) pyrolysis; and b) oxidations, as a function of temperature for $20 \mathbb{C}$ / min heating-rate.

Figure 9. Propagation modes of one-dimensional smoldering combustion.

Figure 10. Results for the front structure of forward smolder in polyurethane foam.

Figure 11. Results for the front structure of opposed smolder in polyurethane foam. 
Figures

a)
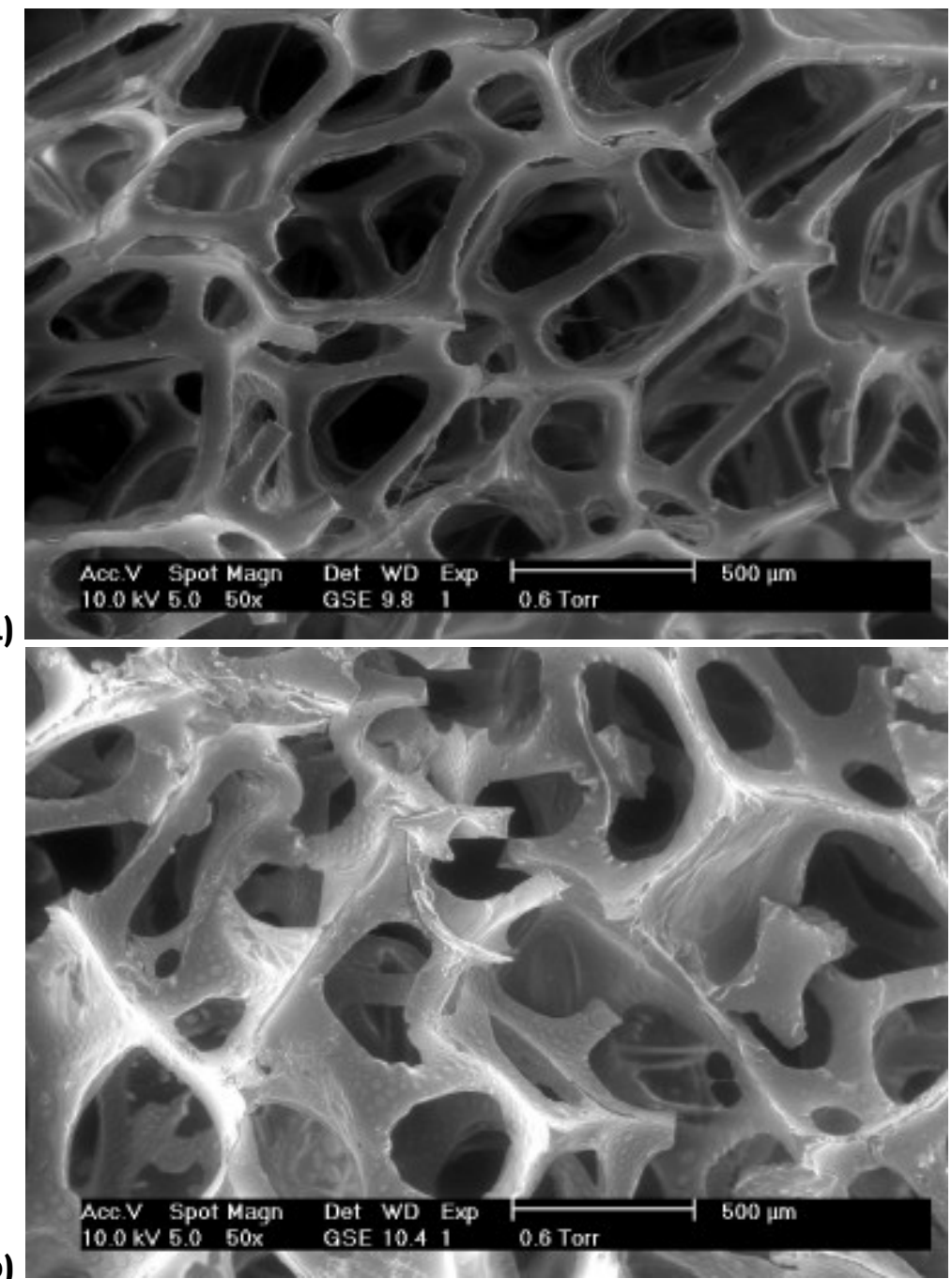

b)

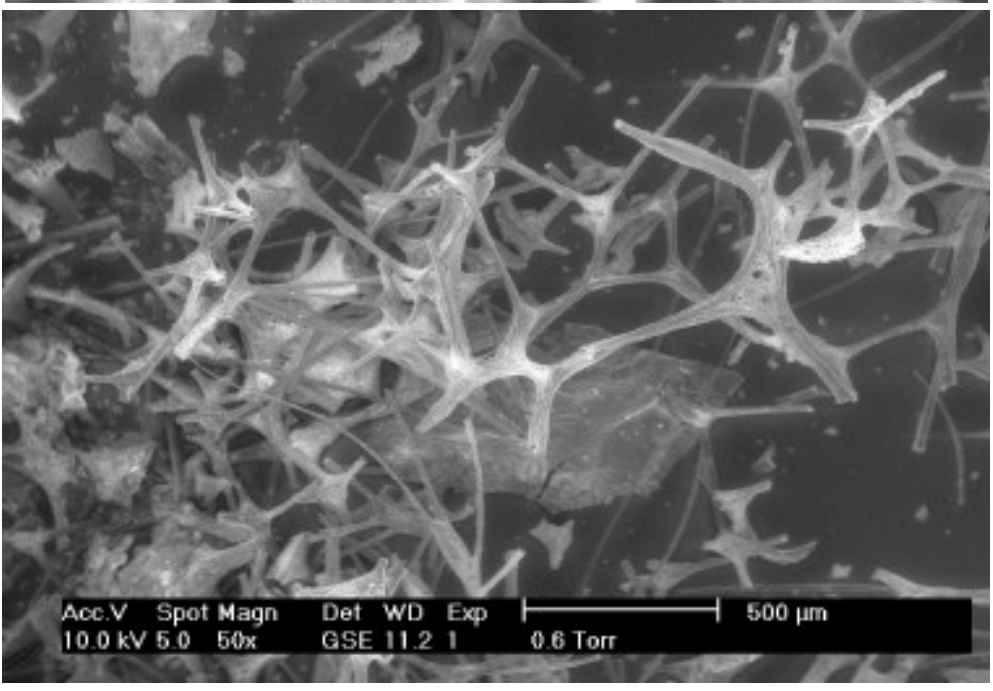

Figure 1 

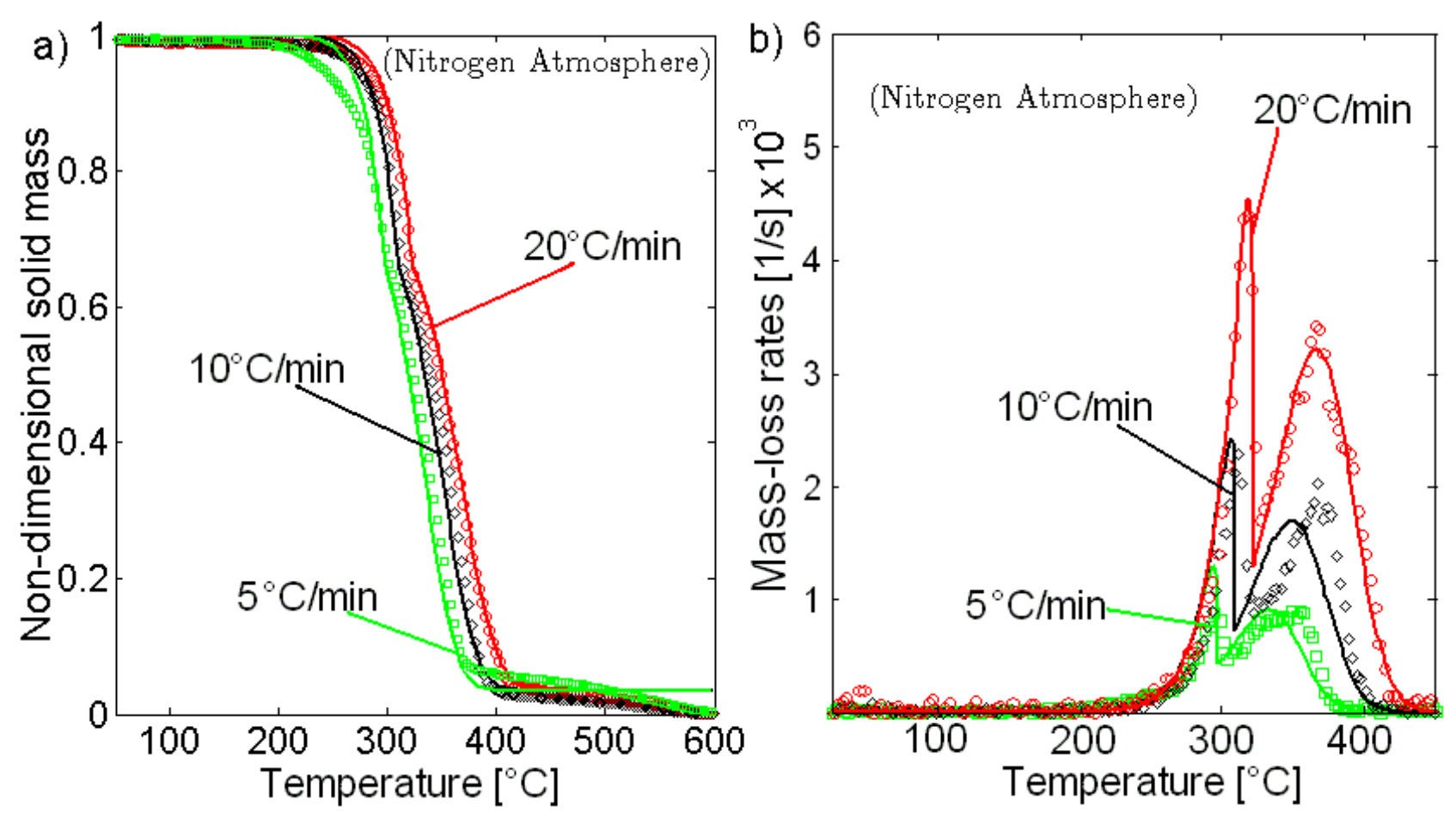

Figure 2.
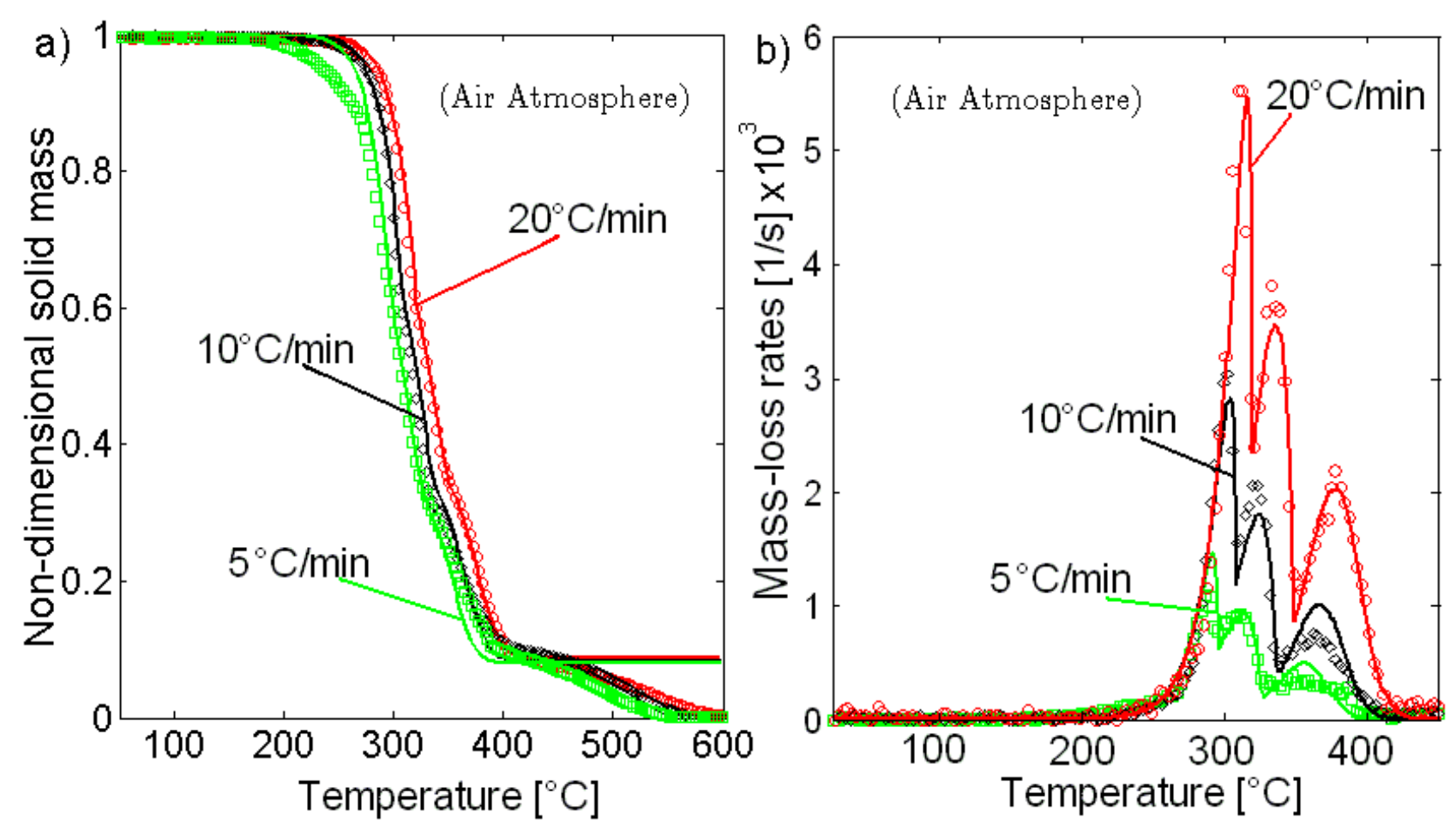

Figure 3 


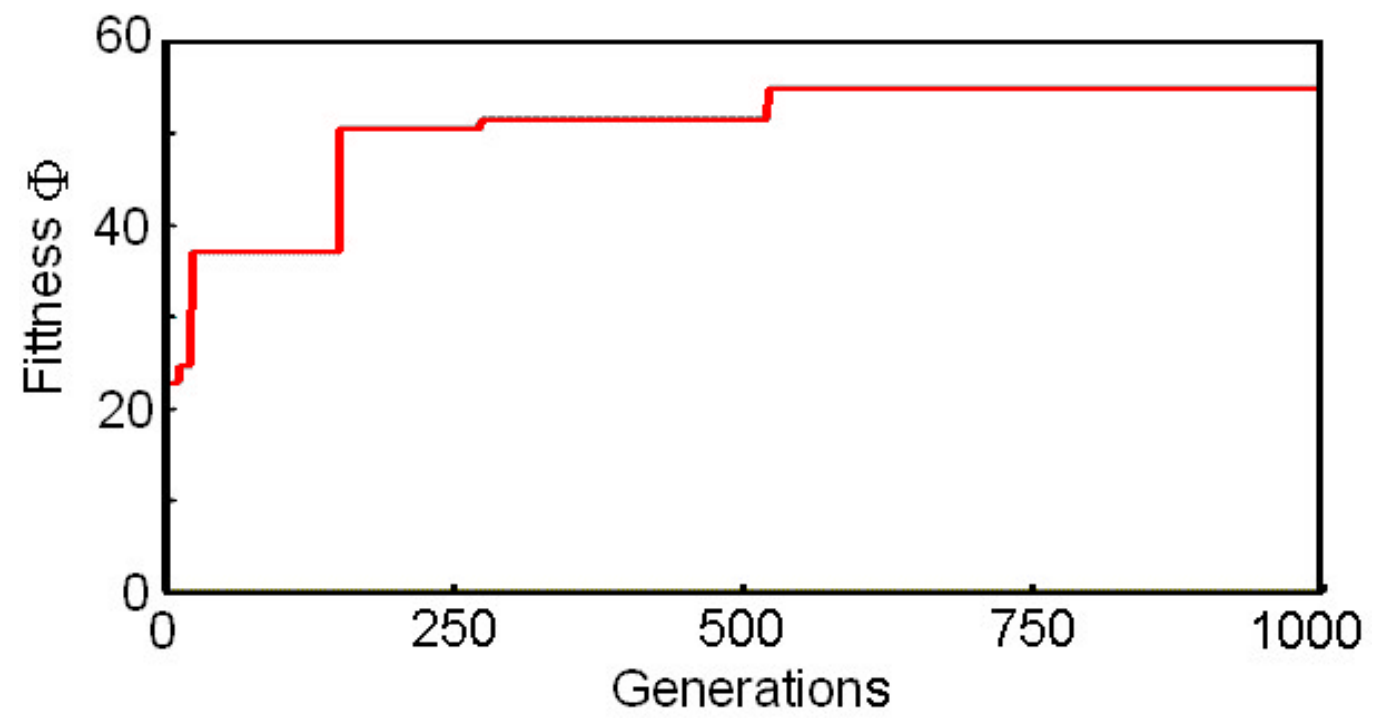

Figure 4.

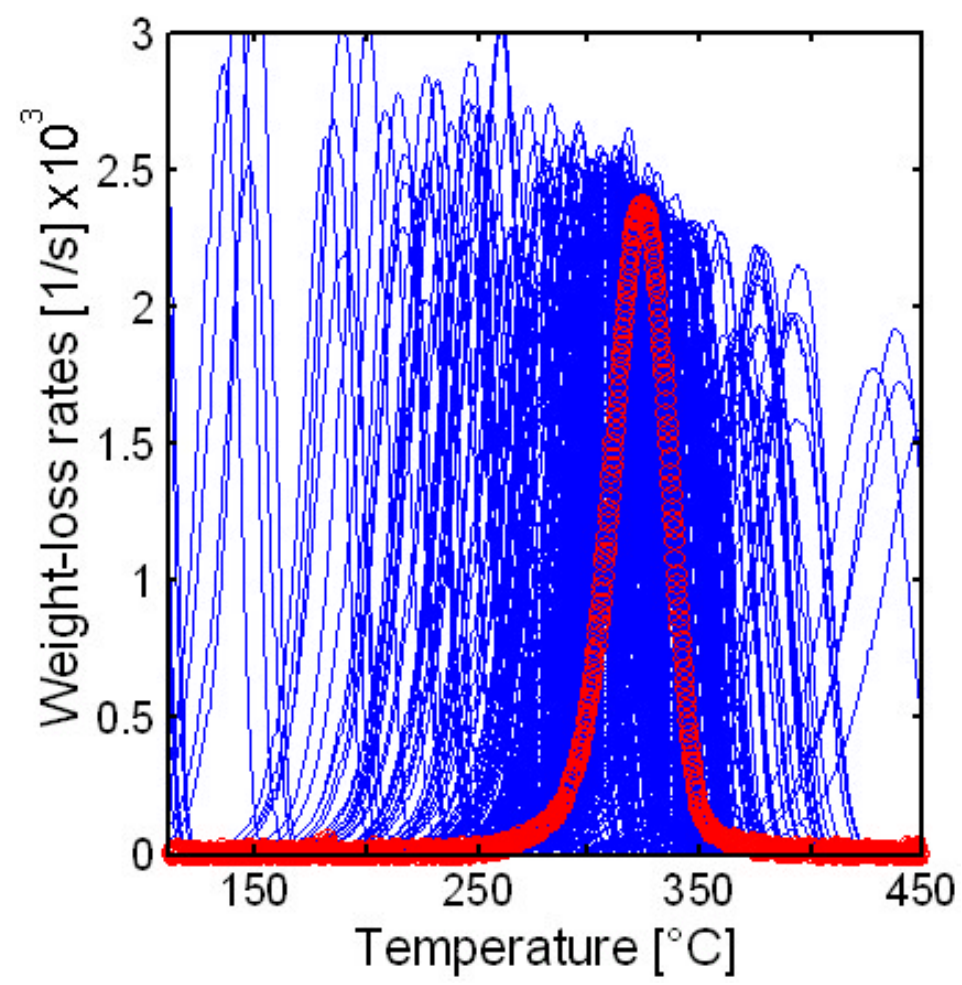

Figure 5. 


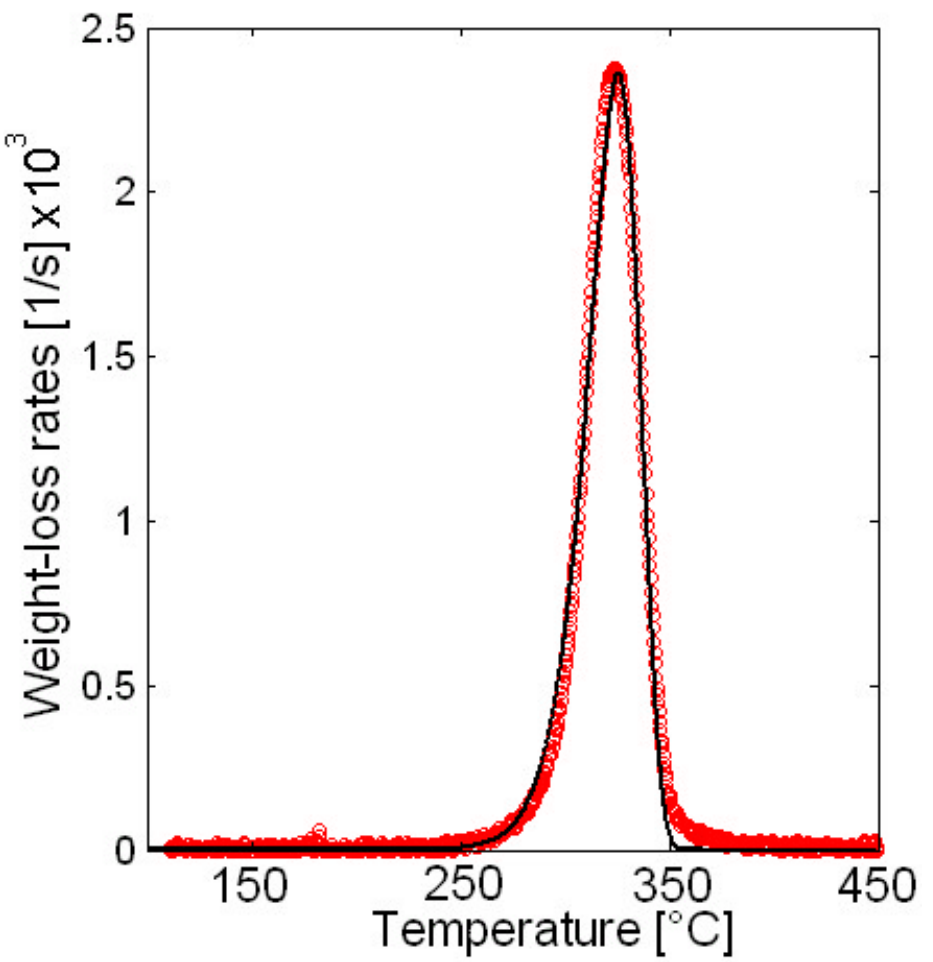

Figure 6 


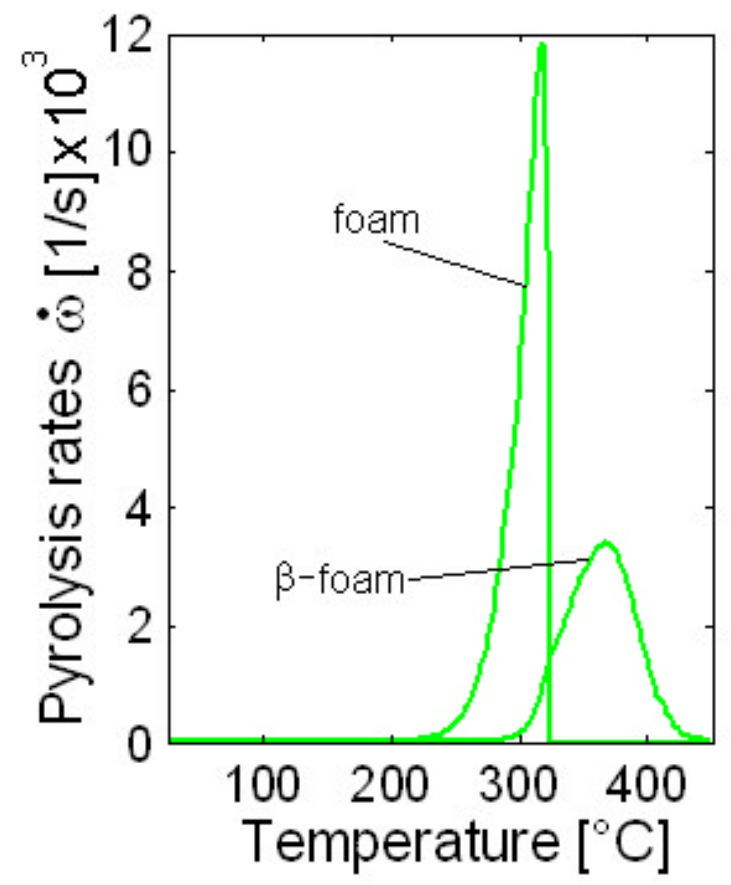

Figure 7.
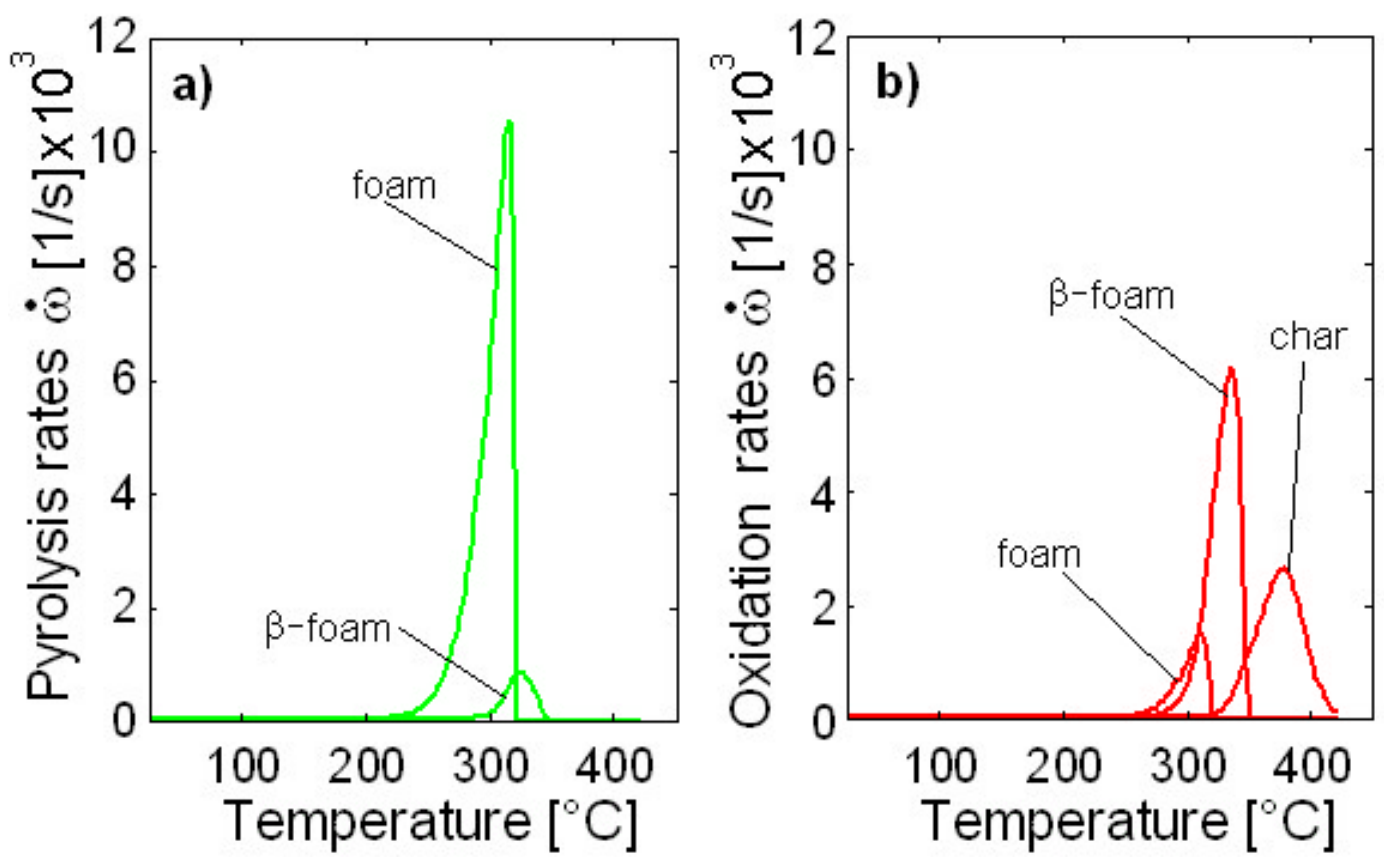

Figure 8. 
Forward Flow

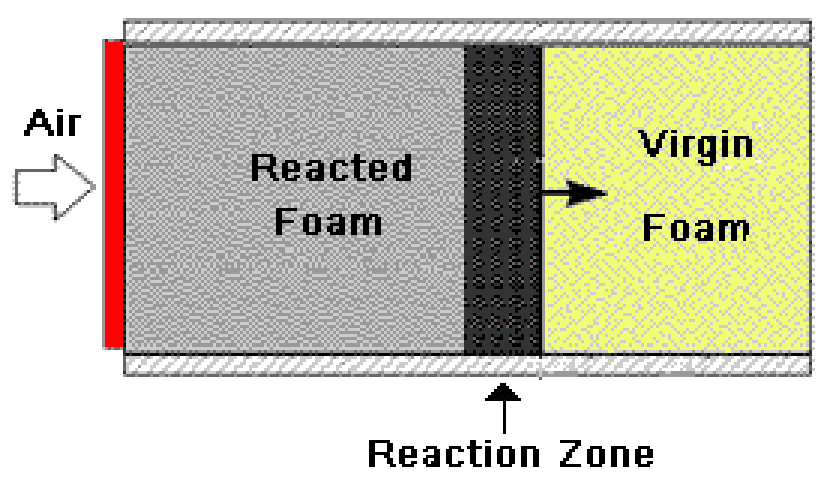

Opposed Flow

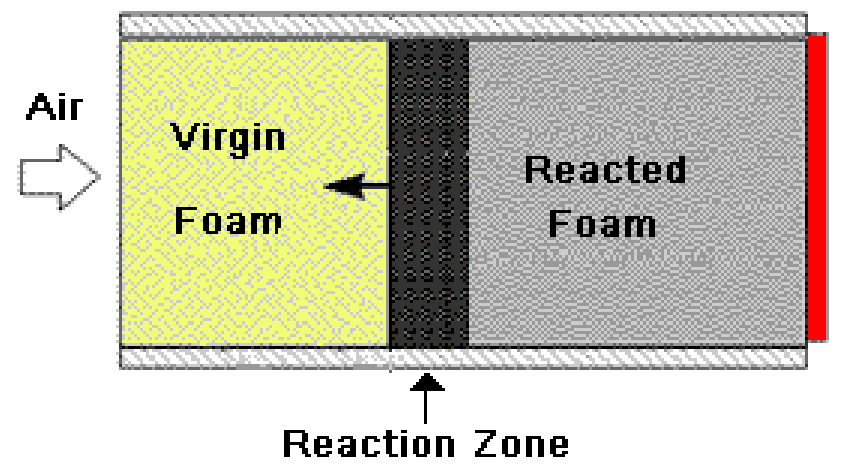

Figure 9 


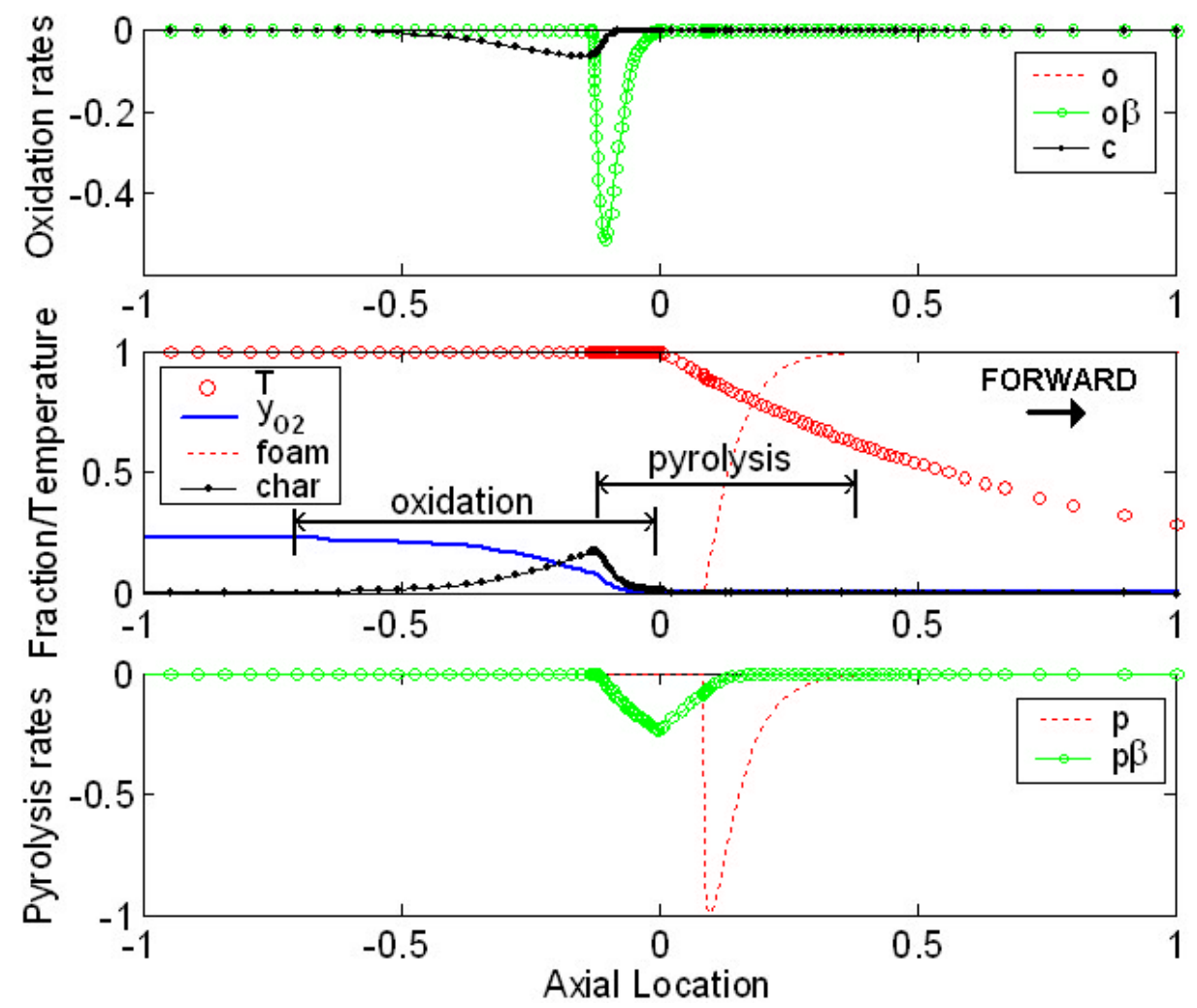

Figure 10.
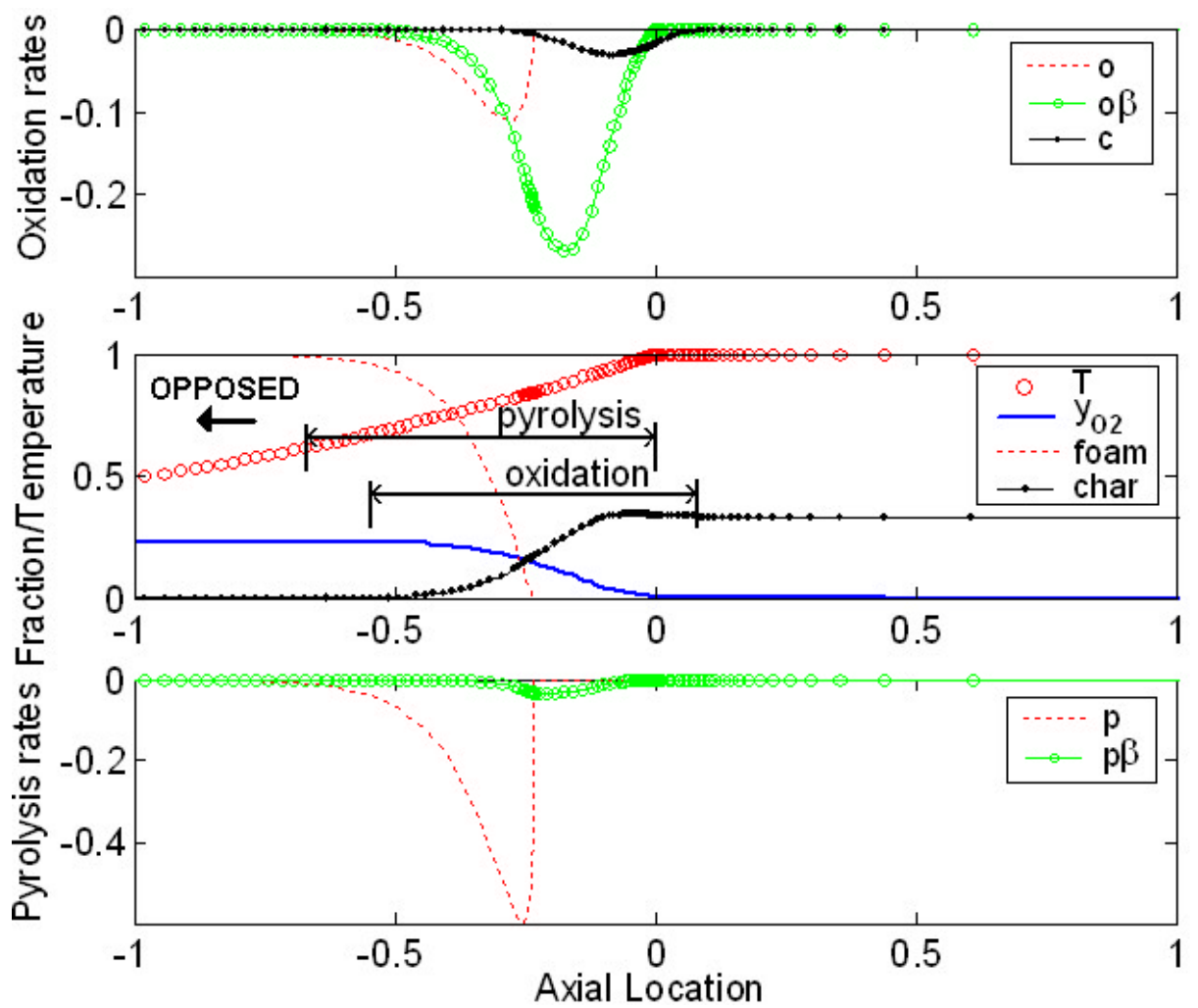

Figure 11. 